\title{
PORPHYRIA
}

\author{
By. Professor Charles Gray \\ King's College Hospital Medical School, London
}

Three types of porphyria are recognized clinically: (I) A congenital, or photo-sensitive, form, (2) an acute intermittent form and (3) a chronic or mixed form. Although on clinical grounds these differ greatly from one another so that they have been regarded as distinct diseases, it now seems possible that this is not so. They are usually regarded as uncommon diseases but it is likely that as they become more widely known they will more frequently be recognized. The porphyrias are characterized by an abnormal excretion of porphyrins or of porphyrin derivatives. Normal urine and faeces contain minute quantities of porphyrins and only small increases in the quantities excreted occur in such conditions as pernicious anaemia, liver disease, lead poisoning, poliomyelitis and various forms of haemolytic anaemia. This. small increase in the normal excretion of porphyrins is termed porphyrinuria and is not regarded as a primary disturbance of porphyrin metabolism. In the true porphyrias there is a major abnormality of porphyrin metabolism and there is usually an excretion of abnormal porphyrins or of their derivatives. However, in some forms of chronic porphyria (porphyria cutanea tarda) there is at least a tenfold and often a thousandfold increase in the excretion of normal porphyrins.

\section{Acute Porphyria}

In. acute, or acute intermittent, porphyria, characteristic episodes of colicky pain and constipation are associated with symptoms referable to the central nervous system. If they are not rapidly fatal the acute episodes may be followed by periods of partial or complete remission lasting a variable time- - sometimes a few days but sometimes several years. The attacks usually, but not always, begin in early adulthood and often seem to be precipitated by the administration of sulphonamides or barbiturates for some incidental condition. The abdominal colics may be very severe and simulate a surgical emergency such as acute appendicitis, ileus, cholecystitis, ectopic pregnancy or a twisted ovarian cyst but the abdomen is not usually rigid.
The involvement of the central nervous system leads to irregularly distributed flaccid paralyses; sometimes involving only a single muscle group sometimes involving most of the striated muscle of the body. The clinical picture is very varied however, and the neurological features may be्. limited to ptosis, a facial palsy, diplopia, disphoniâ or dysphasia. Many cases have been erroneousl ș diagnosed as hysteria, acute psychosis, polio? myelitis or encephalitis. These neurologica捄 manifestations are essentially those of a polyo neuritis and histological studies reveal a patchy degeneration of peripheral nerves and anterios horn cells. When the bulbar centres are affected? there is early respiratory failure and rapid death On the other hand, if recovery occurs it may $B$ remarkably complete even in the most sericis cases. The immediate prognosis is thus difficall to assess, although the long-term prognosis uniformly bad.

Hypertension frequently occurs during the acut\& attack but is often labile and then the alternating periods of hypotension and skin pigmentation which is frequently present may lead to ans erroneous diagnosis of Addison's disease. Oliguriar is a common feature probably because of the restriction of fluid and electrolyte intake which invariably occurs during the acute attack.

Waldenström describes a pure abdominal form户 in which the abdominal symptoms occur without involvement of the nervous system, as well as ao nervous form without the abdominal symptoms? $\mathrm{He}$ also describes a comatose form. Photo-은 sensitivity, an essential feature of the other forms of the disease, is rare but when found is mild in character.

The urine may be normal in colour but is often dark red or brown especially on standing in light $N$ When freshly passed the urine during the attacks always contains porphobilinogen, a colourless compound readily detected by the chloroformo insoluble red pigment formed on adding Ehrlich'sक aldehyde reagent. On standing in light, especially: when the reaction is acid, porphobilinogen is converted to a brown pigment, porphobilin, and uroporphyrin III. These two pigments are often? 


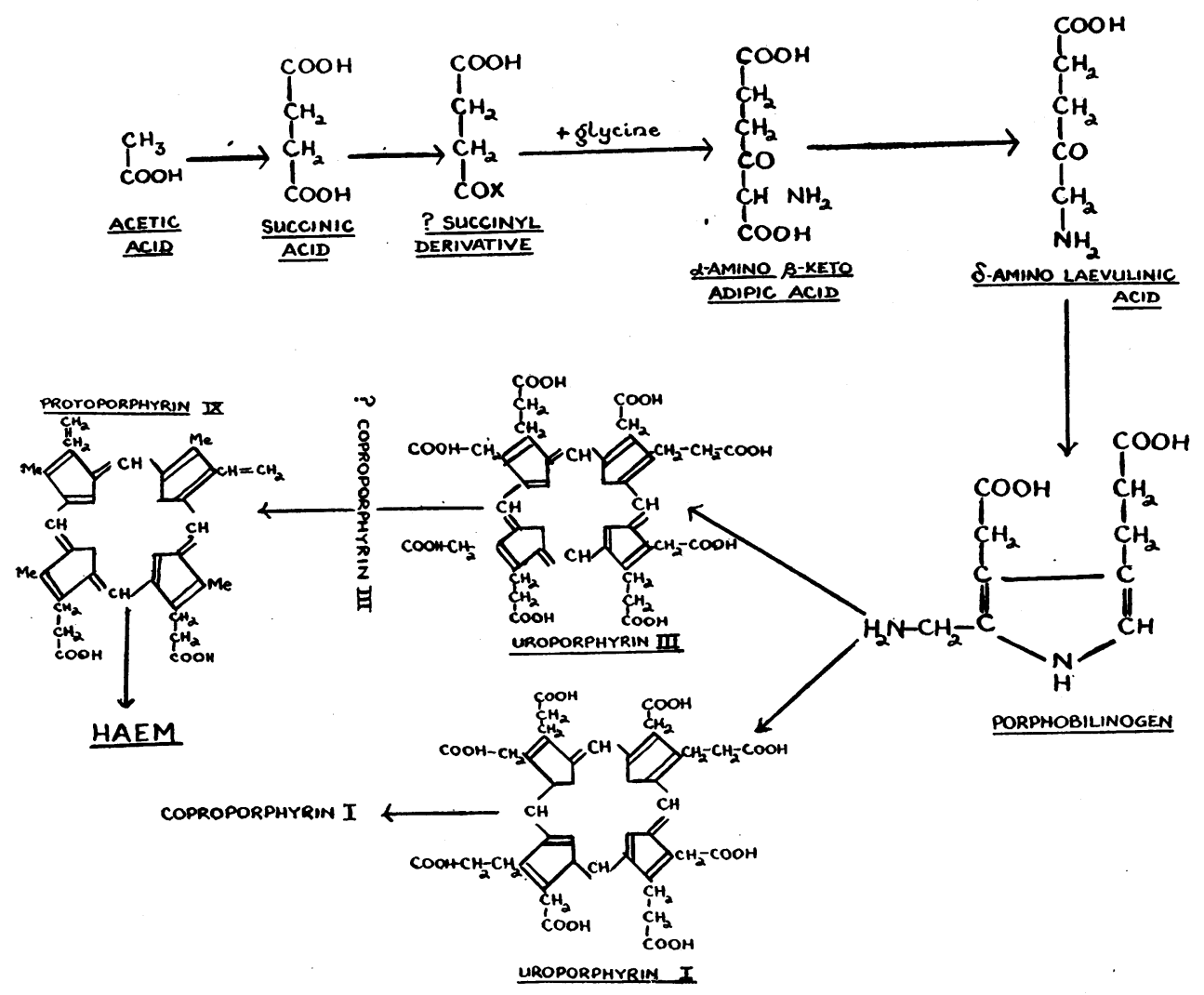

present in the urine as passed and are responsible for the reddish-brown hue. The porphyrin is usually present in the urine as a metal complex, the absorption spectrum of which appears very similar to that of haemoglobin. Some cases of acute porphyria, therefore, have been diagnosed as haemoglobinuria.

\section{Congenital Porphyria}

In congenital porphyria a severe photosensitivity is present at, or soon after, birth. There are no abdominal or central nervous system lesions. The skin exposed to light becomes covered with bullae, crusts and residual scars. The bullae, which contain serosanguinous or seropurulent fluid are succeeded by yellow crusts which gradually turn black and become dense, dry and very adherent. The residual scars may be depressed and pale with the tissue-paper type of epidermal atrophy, but later these scars become hyperpigmented with loss of hair. Secondary infection leads to gross deformation of the skin and underlying tissues so that the fingers become claw-like and restricted in movement. The skin around the digits becomes tightly-drawn leading to a false impression of a fusiform thickening around the joints. Soft tissue destruction may be extensive and one case studied over a long period of time had lost an eye, both ears and much of the nasal tissue. The teeth are red or pink in colour and because of their high content of porphyrin fluoresce bright red in ultra-violet light. At post-mortem the bones are found to be similarly impregnated with porphyrin. The clinical aspects of the condition are identical with those of hydroa oestivali and epidermolysis bullosa but not all patients with one or other of these conditions prove to be cases of congenital porphyria.

Associated with this extreme photo-sensitization there is usually haematological evidence of increased haemolysis with reticulocytosis, greatly increased faecal urobilinogen excretion and sometimes anaemia. Splenomegaly usually develops in the second decade of life or sometimes earlier.

The urine is cherry red or deep burgundy in colour and contains large amounts of porphyrins, mainly uroporphyrin I with smaller quantities of coproporphyrin I and other porphyrins. Although the uroporphyrin I sometimes appears as a colourless precursor, porphobilinogen is not present and the Ehrlich test is negative.

Chronic Porphyria (Porphyria cutanea tarda) In this condition there is a mild photo-sensitivity. 
which, however, does not lead to the severe scarring and deformities characteristic of the congenital form of the disease. Sometimes there are mild abdominal symptoms but no central nervous system lesions are present. Exposure to light, heat or mild trauma leads to a blistering of the exposed skin. The complexion is usually of a dusky bluish-red hue, often with some degree of melanosis and hypertrichosis. The condition is often precipitated by liver disease, either an acute or subacute hepatitis or cirrhosis. Many cases show no clinical or biochemical evidence of active liver disease but are chronic alcoholics.

During attacks the urine may contain protoporphyrin IX or a considerable excess of coproporphyrin III. Between attacks, however, the urinary excretion of porphyrins may be normal but a great excess of either coproporphyrin III or protoporphyrin IX may be found in the faeces. Often there is a reciprocal relationship between the urinary porphyrins and faecal porphyrins. Apparently in these patients the normal route of excretion of these excess porphyrins is via the liver, bile and the gut, but when there is liver damage there is a diversion to the renal route.

\section{Abnormalities of Porphyrin Biosynthesis in the Porphyrias}

During the last decade considerable knowledge has accumulated concerning the biosynthetic pathway of the porphyrins. It is now known that acetic acid is converted in the Krebs cycle to a derivative of succinic acid which can condense with glycine to form $\alpha$-amino $\beta$-keto adipic acid. This acid loses carbon dioxide to form $\delta$ aminolaevulic acid, a carboxy acid containing five carbon atoms and bearing a ketone group and an amino group. Two molecules of $\delta$ aminolaevulic acid condense to form porphobilinogen, a monopyrrolic compound which has long been known as the colourless precursor of porphyrins excreted in acute porphyria, but the structure of which was not elucidated until 1952. Four molecules of porphobilinogen can condense together to form either uroporphyrin I or uroporphyrin III which differ according to the arrangement of the acetic acid and propionic acid side-chains in the four pyrrole ring. Although the uroporphyrins are readily converted in vitro into the corresponding coproporphyrins, and protoporphyrin IX is theoretically derived from coproporphyrin III, there is evidence that the pathway of conversion of uroporphyrin III to protoporphyrin IX and the haem of the haem proteins is not direct and does not involve coproporphyrin III.

Congenital porphyria. Normally the formation of porphyrins from porphobilinogen is so directed enzymically that only a few hundred micrograms of type I porphyrin are produced in contrast to about 200-300 mg. of type III porphyrins required for synthesis of protoporphyrin for incorporation in the haem protein. In congenital porphyria ther⿳亠 is a genetically determined abnormality of this enzymic conversion so that the amounts of type 5 and type III porphyrins are much more nearlys equal, and the excretion of uroporphyrin $I$ an $\Phi$ coproporphyrin $\mathrm{I}$ in this disease may amount to $100 \mathrm{mg}$. or more per day. These type I porphyrins are of no value to the body for synthesis of haem proteins and they are not degraded to bile pigmentse They are therefore excreted or deposited in the body, in the bones and the teeth. The presence of the free porphyrins in the tissues is known to be as $\vec{\omega}$ sociated with the release of histamine and accounts for the photo-sensitivity characteristic of congenita porphyria. It is possible that the presence o $\bar{E}$. uroporphyrin I in the red cells may lead to sensitivity of the red cells resulting in the haemow lysis which is a characteristic feature of the condition. The increased haemolysis is usually $\dot{y}_{\infty}$ accompanied by hyperplasia of the bone marrow so that anaemia is rare. The increased synthesis of haem proteins in the bone marrow is, of course $\overrightarrow{-}$ accompanied by increased quantities of uro $\frac{b}{3}$ porphyrin I which is a by-product of that activity Splenectomy has been reported to cause a dimingle tion in the porphyrin excretion by reducing rate of haemolysis and thereby diminishing need for haemoglobin synthesis and thus reduciong the production of the type I porphyrin by products; this is by no means a constant on permanent result.

Acute porphyria. In acute porphyria the urine often contains a complex mixture of porphyrins the precise nature of which is unimportant because the essential feature of the disease is the excretion of porphobilinogen. In the experimental por phyria induced by Sedormid there is evidence that the-e is a diminution in the synthesis of catalasea haem protein, and it is assumed that because of $\mathrm{B}$. this block in synthesis the excess porphobilinogen is excreted in the urine. There is no evicierct that a similar mechanism is responsible for the humaro disease. It is much more probable that porphobilinogen formation is in excess of that required for normal haem synthesis. Indeed recent work suggests that in acute porphyria the conversion of $\delta$ aminolaevulic acid to porphobilinogen is greatly increased and that an increased amount of $\delta$ aminolaevulic acid is formed from glycine anf succinic acid. An alternative possibility is a decreased metabolism of $\delta$ aminolaevulic acid viक्ष pathways other than porphobilinogen.

For many years the view has been held that the lesions of the nervous system and the abdomina $\bar{b}$ colic were due to direct action of porphyrins or 
the nervous system and gut respectively. There is no evidence that porphyrins have either of these actions when they are in the pure state and neither porphobilinogen nor $\delta$ aminolaevulic acid has any pharmacological effect. It is probable, therefore, that the lesions are due to some enzymic abnormality in the glycine-succinate metabolism of the central nervous system and that the abdominal colics perhaps may be related to a similar impairment in the autonomic nervous system. Such a view would account more readily for the extremely patchy and diverse nature of the clinical lesions in the disease.

Porphyria cutanea tarda. It is impossible with the present state of knowledge to speculate on the nature of porphyria cutanea tarda. For some time this variety of the condition has been regarded as a separate entity from the other two forms of the disease. The occasional occurrence of mild photosensitivity in acute porphyria and a few reports indicating that the clinical condition in a patient with porphyria cutanea tarda may change into that of acute porphyria, suggests that these two forms may be very closely related. Indeed recent studies have suggested that in all forms of porphyria the body pools of $\delta$ aminolaevulic acid and porphobilinogen are considerably increased. It is not impossible that the same fundamental lesion of porphyrin synthesis may be present in all forms of porphyria but that in the congenital form of the disease and in the porphyria cutanea tarda form there has been an enzymic adaptation resulting in the disposal of the excess porphobilinogen by its conversion into other porphyrins which are then excreted.

\section{The Diagnosis of Porphyria}

Until lately, the view has been held that in congenital porphyria the excreta contained free porphyrins of type I, while in acute porphyria the porphyrins, mainly of type III, were excreted partly as a metal complex and partly as the colourless precursor ' porphobilinogen.' It is now known that the porphyrins in the excreta are in fact complex mixtures, the precise compositions of which are still a subject of research so that complex quantitative and qualitative investigations are usually unnecessary for clinical purposes.

In acute porphyria the urine may be red-brown or normal in colour. The essential test is for the presence of porphobilinogen in the freshly passed urine which on the addition of Ehrlich's aldehyde reagent will give a red pigment insoluble in chloroform. This test is often positive even after the urine is diluted one in ten or more. The red pigment formed from ' urobilinogen' on the addition of Ehrlich s reagent is extractable by chloroform. Moreover, a positive Ehrlich's test due to increased urinary urobilinogen will always be accompanied by a positive Schlesinger reaction. If the urine is not fresh the porphobilinogen may partly or wholly have been converted to a mixture of porphyrins, usually present as a metal complex. This has a two-banded spectrum superficially resembling that of haemoglobin, but which is unaffected by reducing reagents such as sodium hydrosulphite.

Congenital porphyria is readily diagnosed from the red or pink colour of the urine which on spectroscopic examination reveals the typical fourbanded spectrum of a free porphyrin, usually ether insoluble and with absorption maxima at about $612,560,539$ and $504 \mathrm{~m} \mu$. In ultra-violet light the urine fluoresces an intense red. It is reported that occasionally in congenital porphyria the porphyrins are also excreted as a colourless precursor, porphyrinogen, which is different from porphobilinogen. Porphyrinogen is converted by light and air or other reducing agents into porphyrins but does not react with Ehrlich's reagent.

The diagnosis of porphyria cutanea tarda is often more difficult since during remission the urine may be normal and the only abnormality is the excretion of excess porphyrin in the faeces. It is necessary, therefore, to examine both urine and faeces, the former by spectroscopic examination in a depth of at least 4 in. and the latter by a simple technique such as is used in the routine spectroscope examination of faeces for occult blood. That of Snapper is particularly valuable since it separates the iron-containing derivatives of haem from the porphyrins. Often such simple tests will suffice to confirm the diagnosis, but sometimes in cases of doubt it is better to refer the materials to some laboratory specializing in this kind of investigation. In acute phases the plasma itself may fluoresce in ultra-violet light.

\section{Treatment of Porphyria}

The treatment of porphyria is highly unsatisfactory. The favourable results reported using clacium, various vitamin preparations, especially of the B. complex, cortisone, ACTH and, more recently, BAL have not been confirmed and their effects have probably been confused with spontaneous remissions in the disease. In the state of present knowledge, treatment of all forms of porphyria can only be symptomatic. Barrier creams, avoiding sunlight and antibiotics for infected lesions, are all that can be offered to the patient with congenital porphyria or porphyria cutanea tarda. In congenital porphyria splenectomy may perhaps be considered if there is evidence of considerably increased haemolysis.

Strict abstinence from sulphonamide and barbiturate drugs must be a rule for the patient with acute porphyria, the treatment of which must also 
of necessity be symptomatic. Orthopaedic treatment may be necessary to minimize the effect of the paralyses. Pethidine and other morphine substitutes may be needed to alleviate the abdominal pain. The poor nutrition and vomiting which may sometimes accompany the acute attacks may lead to sodium and even potassium deficiency and such patients may require strict control of their fluid, electrolyte and nutritional intake.

The disease is undoubtedly transmitted by heredity and the urine of all relatives of a case of acute porphyria should be tested for porphobilinogen. Latent porphyria is frequently found and such individuals should be warned to avoid barbiturates and sulphonamides. They should carry a card to inform any doctor that they are sufferers from the disease so that the condition ma be borne in mind should any question arise of diagnosing an acute surgical emergency.

\section{BIBLIOGRAPHY}

BORST, M., and KOENIGSDORFFER, H. (1929), 'Unteruschungen über Porphyrine,' Leipzig, Hirzch.

DOBRINER, K.; and RHOADS, C. P. (1940), Phys. Rev., 20, 4I 1 P FISCHER, H., and ORTH, H. (1937), 'Die Chemie des Pyrrots Band II,' Leipzig, Akademische Verlagsgesellschaft M.B.H.

MUIR, H. M. (r954), 'The Chemical Pathology of the Anim Pigments,' Cambridge, University Press, p. 4.

POPJAK, G. (1955), ' Royal Institute of Chemistry Monograp No. 2.'

RIMINGTON, C. (1952), Acta med. Scand., 143, x6r, 177.

VANNOTTI, A. (1954), 'Porphyrins,' translated by C. Rimingtoff? London, Hilger \& Watts.

WATSON, C. J. (I954), 'Advances in Internal Medicine,' Vol. VP Year Book Publishers Inc., Chicago.

WATSON, C. J., and LAWSON, E. A. (1947), Phys. Rev., 27, 47 $\overrightarrow{8.0}$

\section{CARDIAC DISEASE}

(Postgraduate Medical Journal)

Price 3s. 10d. post free

INTRODUCTION

Walter Somerville, M.D., M.R.C.P.

ANGIOGRAPHY

J. Norman Pattinson, M.B., B.Chir., D.M.R.D., F.F.R.

BEDSIDE DIAGNOSIS OF CONGENITAL HEART DISEASE

Walter Somerville, M.D., M.R.C.P.

SURGICAL TREATMENT OF CONGENITAL HEART DISEASE

W. P. Cleland, M.R.C.P., F.R.C.S.

PREGNANCY AND RHEUMATIC HEART DISEASE

Samuel Oram, M.D., F.R.C.P.
DRUG TREATMENT OF HYPERTENSION

E. G. McQueen, M.B., M.R.C.P., and F.H. Smirk, M.D., F.R.C.P.

TREATMENT OF BACTERIAL ENDOCARDITIS

Ian G. W. Hill, C.B.E., T.D., F.R.C.P.E., M.R.C.P., F.R.S.E.

THE MANAGEMENT OF COR PULMONALE J. F. Goodwin, M.D., M.R.C.P.

THE CARDIAC RISK IN ANAESTHESIA AND SURGERY

Graham W. Hayward, M.D., F.R.C.P.

Published by

THE FELLOWSHIP OF POSTGRADUATE MEDICINE

60, Portland Place, London, W.1

\section{RUTHIN CASTLE, NORTH WALES}

A Clinic for the diagnosis and treatment of Internal Diseases (except Mental or Infectious Diseases). The Clinic is provided with a staff of doctors, technicians and nurses.

The surroundings are beautiful. The climate is mild. There is central heating throughout. The annual rainfall is $\mathbf{3 0 . 5}$ inches, that is, less than the average for England.

The Fees are inclusive and vary according to the room occupied.

For particulars apply to THE SECRETARY, Ruthin Castle, North Wales.

Telograms: Castle, Ruthin.

Telephone: Ruthia 